\title{
State Management in Building a New Rural Area in Vietnam: A Research in Muong Tra District, Dien Bien Province
}

\author{
Pham Nguyen My Linh (Corresponding author) \\ University of Manitoba, Manitoba, Canada \\ Pham Thai Long \\ Rmit University, Vietnam \\ Tran Le Quoc Khanh \\ University of Manitoba, Manitoba, Canada
}

Nguyen Thi Thu Hương

Academy of Finance, Hanoi, Vietnam

Do Thi Nang

Academy of Finance, Hanoi, Vietnam

Nguyen Quang Sang

Academy of Finance, Hanoi, Vietnam

Received: March 16, 2021 Accepted: April 8, 2021 Published: X, 2021

doi:10.5296/emsd.v10i2.18415 URL: https://doi.org/10.5296/emsd.v10i2.18415

\begin{abstract}
Vietnam's rural area accounts for $65 \%$ of the population, providing over $70 \%$ of the labor force for the national economic sectors, of which $51 \%$ of the workforce is working in the
\end{abstract}


agricultural sector. This is a sector that creates many jobs for rural areas, contributing $30 \%$ of GDP to the national economy. In the current period and the coming years, Vietnam's rural agriculture still plays an important role in the country's socio-economic development. However, Vietnam's rural areas are facing new difficulties and challenges, the growth of agriculture is slow and unsustainable; Farmers' living standards are low and slowly being improved; The disparity in living standards between urban and rural areas, and between regions and regions is tending to expand, especially in mountainous rural areas with unfavorable natural conditions, with many ethnic minorities living together, the gap between the rich and the poor is increasing. That creates conflicts and instability in society, threatening the sustainable development of the country. This article focuses on analyzing the state management situation on new rural construction in Muong Cha district, Dien Bien province, Vietnam, pointing out the achievements, limitations, causes and some recommendations for improvement. State management on the construction of a new countryside in Muong Cha district, Dien Bien province, Vietnam in the context of world economic integration.

Keywords: State management, Construction, Rural area, Vietnam

\section{Introduction}

On August 16, 2016, the Prime Minister of Vietnam signed and issued Decision No. 1600 / QD-TTg on approving the National Target Program on New Rural Construction and Decision No. 1980 / QD. -TTg dated October 17, 2016 on promulgating the national set of criteria for a new rural commune for the 2016-2020 period. This is a comprehensive and comprehensive program on socio-economic development, politics and security and defense with eleven contents and nineteen criteria to create remarkable changes in the lives of people in rural areas in Vietnam.

Muong Cha District, Dien Bien Province, Vietnam, after four years of implementing the National Target Program on New Rural Construction, the appearance of Muong Cha rural area has gradually changed compared to the time before the program started. The new rural program has become a large-scale campaign, mobilizing the entire political system to participate. In particular, the subjective role of the community in the construction of a new countryside is being promoted, reflected in the high supportive support in new rural construction activities such as land donation, property donation, voluntary site clearance, contribute efforts to build rural roads, irrigation and other social welfare projects, directly participate in supervising construction works in the area. By the end of 2020, the whole district has one commune, meeting 15-19 criteria; one commune meets 10-14 criteria; nine communes meet 5-9 criteria; no commune meets less than five criteria. Thus, after four years of implementing the program, the whole district reaches 90 criteria; On average, each commune reaches 8.18 criteria, the average growth rate per year is 0.64 criteria per commune. The gap between the reality and the program's objectives is still quite far, the state management of new agricultural construction in Muong Cha district still has many shortcomings, leading to the implementation of the goals is not synchronized.

In this situation, to contribute to promoting socio-economic development in rural Vietnam in a sustainable direction requires an increasing role of state management on new rural 
construction in Vietnam in general and in the district. Muong Cha, Dien Bien province in particular is a very necessary issue. Stemming from the above practice, the authors want to share their views and propose a number of recommendations with scientific and practical basis on this issue.

\section{Literature Review}

Research by Kristen E. Looney (2015) shows that although initially focused on rural participation and moderate change, the new socialist rural has evolved into a top-down campaign aimed at demolition and reconstruction of villages. Three factors shaped this process: the strength of bureaucracy, the weakness of rural institutions, and the shifting of national policy priorities. After gaining status as a model, Ganzhou's rural policy became more ambitious and politicized, leaving less space for participation. This insight shows that there are both benefits and costs to the Chinese policy process. Despite the advantages of policy innovation, expanding local trials can actually undermine their success. The goal of building a new countryside is to focus on rural economic development, quickly increase people's income, invest in construction and upgrade infrastructure, especially transport, irrigation, schools, and other social welfare works, improving the people's material and spiritual life, protecting the ecological environment. Considering the construction of a new countryside as the goal and requirement of sustainable development as well as an urgent task and a policy of particular strategic importance in the Party's deeply humane revolutionary cause. and our State (Thu Chung, 2011).

Song Hong Yuan (2012) balances urban and rural development, economic theory and social analysis on building a new socialist countryside, new rural standards, modern agriculture and systems its creation, implementing high quality food industry project, developing rural tourism, establishing modern rural communication system, fostering new farmers, strengthening basic rural education village, develop vocational training for farmers, increase income and expand consumer demand, strengthen infrastructure construction in rural areas, power the district economy, establish a system ensure agricultural investment, etc. A district meets the new rural standard, it must satisfy 4 conditions: 1. Having registered a district meeting the new rural standard and being included in the implementation plan by the provincial People's Committee; 2. 100\% of the communes meet the new rural standards as prescribed; 3 - Having $100 \%$ of the criteria that rural districts will only meet the prescribed standards; 4- There is no outstanding capital construction in new rural construction. After being recognized as meeting new rural standards, communes and districts continue to improve the quality of criteria and build a model new countryside under the guidance of competent authorities. Presidents of the People's Committees of provinces consider, recognize and announce the new rural standards in the communes. The Prime Minister reviews, recognizes and announces the district's new rural standard; provincial towns and cities complete the task of building a new countryside (Thuy Hang, 2017).

According to the author Tue Man (2019), it is necessary to strengthen the training and retraining of cadres, reporters, editors and reporters to meet the requirements of the task of building a new countryside. Regularly renewing content, diversifying propaganda forms, 
focusing on forms of direct propaganda. The news agencies, the press need to create forums for readers, managers, experts, farmers to share their views, opinions, experiences ... in building a new countryside. Determining that building a new countryside is a regular and continuous process, in order to improve the quality of life for rural people, Ha Nam province focuses on leadership, direction and mobilization of resources to improve quality. new rural criteria at commune and district levels, aiming to build a new rural commune, a model new countryside; propose solutions to develop production, create jobs, and increase income for people. Synchronously deploy production development solutions, considering this a key task during the process of building a new countryside; to step up the concentration of land to develop clean agricultural products for satellite cleaning, linking chains with establishments and enterprises in production and consumption of agricultural products and the speed of restructuring of rural labor, creating more New, stable and high-income jobs for people (Dao Phuong, 2020)

The author Nhat Bac (2020) also thinks that the construction of a new countryside is a continuous and long-term process. In particular, it is necessary to quantify the criteria, build the criteria suitable to practical conditions, resources of the locality, each region, each region in terms of geography, history, culture, especially qualifications. economic development. The set of criteria needs 'hard', 'soft' criteria for easy implementation. New rural construction in China is a kind of macroeconomic development strategy aimed at developing sustainable rural settlements. More attention should be paid to farmers' future livelihoods in the process of developing sustainable rural settlements. Based on the analysis and complexity of Chinese rural problems, building new rural areas in China will be an arduous task and a long way to go (Wen Bao, 2011).

Author Minh Thu (2017) proposed a solution to perfecting the state management on new rural construction is to strengthen inspection and supervision in new rural construction; continue to promote the role of criticism and supervision of the Fatherland Front, socio-political organizations and population communities towards building a new countryside. Periodically, organize surveys on people's satisfaction with the progress and results of new rural construction in the area. By combining China's new financial system for transferring payments to poor local governments with administrative reform, strengthening internal project reviews and efforts to increase rural incomes through mix investing in infrastructure, agricultural specialization, expanding social welfare and accelerating urbanization (Anna L. Ahlers, 2009).

\section{Method}

The authors mainly use descriptive statistical methods to analyze the reality, results and limit the state management situation on new rural construction in Muong Cha district, Dien Bien province, Vietnam. Data collected and aggregated from the Department of Finance - Planning, State Treasury, Inspector, Department of Agriculture and Rural Development, Muong Cha District Fatherland Front Committee, Dien Bien Province, Statistical Yearbook Dien Bien Province 2019, Vietnam. 


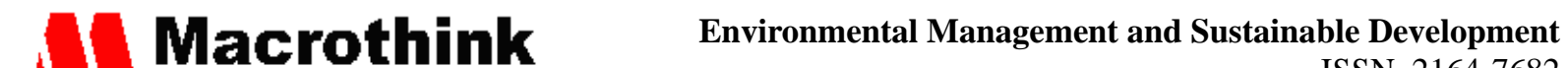 \\ ISSN 2164-7682 \\ 2021, Vol. 10, No. 2}

4. State Management Conditions in Building a New Rural Area in Muong Cha District, Dien Bien province, Vietnam

\subsection{The Natural Socio-economic Conditions of Muong Cha District Affect the State Management of New Rural Construction}

\subsubsection{Natural Conditions and Administrative Structure}

With a natural area of 118,989.49 hectares and advantages of location, Muong Cha has conditions for rapid socio-economic development, urbanization and modernization of rural agriculture, becoming an important factor. to focus on promoting the development of economic axis NH12 and Dien Bien province (Department of Statistics Dien Bien Province, Vietnam).

As a district with a large natural area, the topography is mainly high mountains, the average height above sea level from $350 \mathrm{~m}$ to $1,500 \mathrm{~m}$ has many basins, in general the terrain difference is large, the whole district is divided into 3 main regions: lowland, highland and border areas. The terrain strongly divides the steep slope, which adversely affects agricultural production and infrastructure investment (Department of Statistics of Dien Bien Province, Vietnam).

Muong Cha is located in a tropical climate, annually influenced by two large air masses: dry, cold northern air and southern air (March, April and May are influenced by the southwest air mass. Dry and hot greatly affect agricultural production.) Hot and humid, so the climate here is divided into two distinct seasons: the cold and dry season from November of the previous year to April of the following year, temperature and quantity low evaporation, little rain; Hot and humid season from May to October, high temperature, heavy rain, large evaporation, and high humidity. Average rainfall is from 1,600 to $1,700 \mathrm{~mm}$ per year, the highest is $4,960 \mathrm{~mm}$, the lowest is $856 \mathrm{~mm}$. Every year, flash floods often happen in the district, causing damage to production and husbandry (Dien Bien Statistical Office, Vietnam).

Muong Cha district with a total of 11 communes and 1 town; The total agricultural land area is $57,000.88$ ha, accounting for $12.53 \%$ of the natural land area, the forest land area is 42,063.59 hectare, accounting for $35.35 \%$ of the natural land area (Statistics Department of Dien Bien Province, Vietnam. ).

Culture and society: Muong Cha district has twelve administrative units including Muong Cha town and communes: Muong Tung, Su Tong, Pa Ham, Hua Ngai, Huoi Leng, Muong Muong, Na Sang, Sa Fur, Ma Thi Ho, Nam Nam, Huoi Mi. Muong Cha is the inhabited area of 13 ethnic groups, of which the H'Mong people account for over $60 \%$, the rest are other ethnic groups to follow the family line of the town. Chinese people live by many jobs such as agriculture, handicraft, small business, etc. Chinese people like the art of theater, during holidays, Tet, Chinese people often organize lion dance, dance. boxing, swing, wrestling, chess, etc. (Department of Statistics Dien Bien Province, Vietnam). 
4.1.2 The Socio-economic Situation of Muong Cha District in the 2016-2020 Period Affects the State Management of New Rural Construction

Muong Cha district is a poor district of Dien Bien province, after more than ten years of building a new countryside, many villages have prospered, renewed $249 \mathrm{~km}$ of rural traffic, and conducted 45 training courses. profession, replicating more than 30 effective production models, developing 32 production farms. There are more than 7,588 households voluntarily donating assets worth over 20,451 million VND and more than 5,489 households donate land with a total amount of over 14,254 million VND. Achieved 12.46 criteria per commune, with $7 / 28$ communes meeting new rural standards. Thanks to these results, people's lives have been fundamentally and sustainably changed (Department of Agriculture and Rural Development, Muong Cha District, Dien Bien Province, Vietnam).

However, like the general situation of the country, besides the achievements, there are still many shortcomings that are the direction and administration of a number of steering committees and management boards at commune and village levels. In the district, it is not really scientific and confusing. Some communes also run after their achievements to reach new rural standards early, causing outstanding burdens on capital construction and infrastructure construction; has not focused on production development planning; Infrastructure has been raised but has not met the needs of the people; The maintenance and maintenance work has not yet had effective solutions, so works are still deteriorating rapidly, especially after natural disasters and floods; The role of the people is not highly appreciated in the implementation of new rural construction.

In addition, the application of resources is still limited, mainly waiting for the state budget, the resources of the people have not been paid attention. The above weaknesses are due to many reasons, but the most fundamental is the role of governance. State management has not been appreciated. The localities that build a new countryside with movement, lack the direction, direction, inspection and control of state agencies. Therefore, many inadequacies have occurred such as low quality and scattered investment projects; indiscriminate capital mobilization, only focusing on infrastructure investment, not focusing on overall goals. That situation has not been seriously investigated and evaluated to have concise solutions to improve efficiency. of implementing the policy of building a new countryside.

\subsection{State Management Situation on Building a New Countryside in Muong Cha District, Dien Bien Province, Vietnam}

4.2.1 Implementation and Propaganda for the Construction of a New Countryside in Muong Cha District, Dien Bien Province, Vietnam

Propaganda work is deployed synchronously, in many diversified forms, suitable for each subject. The Muong Cha district propaganda system has actively coordinated with the agriculture and rural development sector at the same level to promote the direction, orientation and organization of propaganda activities. The District Party Committee for Propaganda and Education has issued guiding documents, orientations and regularly integrated the monthly propaganda orientation for the district and commune ideological and 
cultural agencies to clearly define the contents and forms of propaganda. In particular, the content focused on propagating the Party's undertakings, the policies and laws of the State, the objectives, criteria, roadmaps and steps to develop a new countryside; propaganda and encouragement of emulation movements, major campaigns, such as: The movement "Together to build a new countryside in the period of 2016 - 2020", The campaign "All people unite to build a new countryside" , "All people unite to build a new countryside and a civilized city"; replicating new, typical and advanced factors with a good and creative way of building a new countryside. At the same time, directing associated with strengthening grasping the situation of ideology, public opinion among cadres, party members and people of all ethnic groups in the implementation of guidelines, policies, plans and objectives of Programme; Difficult problems, problems, existing in the implementation process at the grassroots level, actively coordinating to advise the committees, authorities at all levels, and branches to focus on solving and removing. In particular, from 2011 to 2020, the District Party Committee for Propaganda and Education coordinated to conduct three sociological surveys among cadres, party members, people of ethnic minorities in the communes to implement the National Target Program on Agricultural Construction of a new village in the province, to evaluate the results of the Program implementation; thereby serving as a basis for committees, authorities at all levels, sectors to draw experiences in leadership, direction and correction of limited and inadequate issues, to propose further solutions to improve quality and efficiency in implementing the program in each period.

In order to create a unified propaganda and propaganda with focus and guidance, based on the direction documents and instructions of the central and provincial government and the characteristic situation of Muong Cha district, all levels have coordinated. with the agriculture and rural development sector compile all kinds of documents, leaflets, leaflets to serve the propaganda work suitable to each locality, each subject.

The propaganda of visualization, panels, posters, banners and slogans has been widely deployed in the areas; at the same time integrating in cultural, artistic, mobile information activities, and highland shadow projection. The role of the press, information and communication in propaganda activities has been promoted. Dien Bien Newspaper regularly publishes news, articles in regular articles, electronic newspapers, newspapers for upland people. Provincial Radio - Television Station opens and maintains the column "Agriculture Rural", "Ethnicity and Religion" broadcast on radio and television in Mandarin and translates and propagates on broadcast programs. radio and television in the ethnic languages of the province (4 languages: Thai, Mong, Dao, Ha Nhi); co-broadcast on VTV1, VTV5 Vietnam Television Station. Along with that, the provincial portal and websites of branches and localities in the district closely follow the orientation of posting news, articles, propaganda materials on the National Target Program on Agricultural Construction. new countryside and the result of building a new countryside in the province.

Particularly, attention has been paid to oral propaganda and implemented quite effectively. The system at all levels actively coordinated with the agriculture and rural development sector to organize conferences of reporters and propaganda in the right direction. In order to promote the role of the grassroots political system and improve the quality of oral propaganda 
at the grassroots level, the Department of Agriculture and Rural Development cooperated to open 8 training courses on propaganda skills building a new countryside for nearly 500 times of commune officials in Muong Cha district area. On that basis, the contingent of reporters and communicators at all levels closely followed the grassroots organization to organize propaganda activities, mobilize the people in the direction of: "Regularly, continuously, promptly and seriously. focus, key; the content of propaganda and campaign is accurate, complete, easy to understand, practical and effective "; the role of the grassroots political system has been promoted, grassroots cadres and party members have actively participated in propaganda and mobilization of people to participate in building a new countryside; Many grassroots cadres and party members have brought into play an exemplary pioneer character in the implementation, contributed their efforts, money, mobilized and gathered the masses and people to follow (Department of Agriculture industry and rural development, Muong Cha District Fatherland Front, Dien Bien Province, Vietnam).

\subsubsection{Mobilizing Resources to Build a New Countryside}

* Land resources: Muong Cha district has a total natural area of: 118,989.49 hectares; in which: agricultural land 57,000,88 hectares; forest land 42,063.59 hectares; non-agricultural land 2,529,25 hectares; river and stream land 1,024.72 ha; unused land 59,459.37 hectares; The land is divided into four soil groups with 17 types of soil, of which eight types are significant for the agricultural and forestry development of the district: Red yellow humus soil on clay rock; light yellow soil on sandstone; reddish-brown soil on basic magmatic rocks; red brown soil on limestone; yellow red earth on clay stone; light yellow soil on sandstone; alluvial soil and streams; valley land converged by steep products (Department of Agriculture and Rural Development, Muong Cha District, Dien Bien Province, Vietnam).

The land fund suitable for wet rice cultivation of 1,571 hectares accounts for only about $1.32 \%$ of the total natural area, including soil types distributed at slopes below 80; the thick layer is more than $30 \mathrm{~cm}$ thick; mainly alluvial soils (Division of Agriculture and Rural Development, Muong Cha District, Dien Bien Province, Vietnam).

- The land fund suitable for other short-term crops (upland rice, crops, short-term industrial crops ...) accounts for about $8.35 \%$ of the total natural area, including soils with a slope of 8 150 , the layer is over $30-50 \mathrm{~cm}$ thick, mainly the yellow red soil group (consisting of the main types of red yellow soil on Fs clay and yellow red soil on Fq sandstone) Dien Bien, Vietnam).

- The land fund suitable for the development of perennial trees by the mode of agroforestry accounts for about $2.25 \%$ of the total natural area; including soil types distributed at the slope from 150 to 250 , layer thickness above $50 \mathrm{~cm}$. Mainly the group of yellow red soil and pale yellow humus group on sandstone (Department of Agriculture and Rural Development of Muong Cha District, Dien Bien Province, Vietnam)

- The land fund for forestry development accounts for about $35.35 \%$ of the total natural area, including land on a slope above 250 and a part of land on a slope less than 250 but with a soil layer less than $50 \mathrm{~cm}$ thick (Room Agriculture and Rural Development Muong Cha District, Dien Bien Province, Vietnam). 


\section{Ml Macrothink}

Environmental Management and Sustainable Development

ISSN 2164-7682

2021, Vol. 10, No. 2

Thus, most of Muong Cha's land bank is suitable for forestry development. This land fund needs to be used thoroughly, greening the barren hills and mountains to soon make the forestry sector a major contributor to the economic growth of the district, and at the same time ensure the primary protection function. sources for the entire region. The land fund is suitable for agricultural development, so attention should be paid to the application of advanced techniques in production to improve crop quality and productivity. Maximize the capacity of suitable land fund to develop perennial crops under the mode of agroforestry, ensuring sustainable agricultural development. The expansion of the land fund for the development of food crops and crops must go hand in hand with the development of irrigation, soil water retention and soil protection and improvement measures in order to bring about high efficiency.

* Water resources: Water resources of Muong Cha district are mainly surface water sources in the headwaters of Da river basin, including a number of main river systems: Nam Phap Stream, Nam Chim stream, Nam stream. Lay. Muong Cha district has abundant water resources, a large basin capable of exploiting irrigation, constructing small and medium hydropower projects to meet the living and production needs of the people.

\section{* Natural resources:}

According to survey data, Muong Cha district has the following minerals and materials:

- Muong Tung coal point, including the following ore points: Huoi Say coal point (Muong Tung): there are three coal seams of 0.1 to $0.3 \mathrm{~m}$ thick, extending intermittently about $6 \mathrm{~km}$. Nam Pien coal site (Muong Tung). In Na Pheo, a 1.8m thick coal seam has been discovered with a reserve of about 2 million tons (Statistical Office of Dien Bien Province, Vietnam).

- Pirit Na Pheo site: surveyed three ore bodies with maximum thickness of $65-70 \mathrm{~cm}$, continuous length of nearly $300 \mathrm{~m}$, forming a zone of nearly $50 \mathrm{~m}$ wide and $5 \mathrm{~km}$ long. The ore sample has a sulfur content of about 37 - 50\% (Statistical Office of Dien Bien Province, Vietnam).

- Nam Chim hot water point (Ma Thi Ho): T0: 390C, Q: 0.551/s (Department of Statistics Dien Bien Province, Vietnam).

- Potential for construction materials: Construction stone quarries are scattered in areas in the district, mainly in Muong Muong commune, Huoi Leng, Muong Tung, Hua Ngai, Su Tong. The reserve is quite large, but due to manual exploitation, it has not been exploited effectively.

In addition, a number of mines were discovered such as: Angtimo mine in Muong Muong commune; copper mine in Muong Tung; iron mines in Chieu Ly with these mines have significant reserves.

* Forest resources: Total forested land area of Muong Cha district by 2018 is 42,063.59 hectares; In which protection forest 23,704.26 hectares, production forest 18,359.33 hectares. Forest coverage reaches 36.05\% (Division of Agriculture and Rural Development, Muong Cha District, Dien Bien Province, Vietnam). 
Some valuable timber with high economic value such as paved, amorphous and chestnut only remain in high, remote and dangerous terrain. There are also shrubs, scattered timber trees, low-mountain tropical high-altitude grasslands and medium-mountain tropical sub-tropical. In addition, there are also special plants such as ant wings, bamboo. There are very few animals, mainly deer, monkeys, wild pigs. Along with the deforestation caused by indiscriminate exploitation is an alarmingly rapid decline of forest products, leading to ecological imbalance, erosion, flash floods, landslides, great losses in the rainy season and water shortages. severe dry season. However, so far, the district has tried to do well the zoning, protection and allocation of forest land to rural households, well implemented the project of 5 million hectares of forest, the coverage in 2018 reached 36.05\%. (Division of Agriculture and Rural Development, Muong Cha District, Dien Bien Province, Vietnam).

\section{*Human Resources:}

The whole district has 9,081 households with the average population of the district in 2018 is 47,136 people, on average, 5.19 people/household; life expectancy at birth is 68 years; population density reaches 39.6 people/ $\mathrm{km} 2$; population distribution is uneven, population mainly concentrated in lowland areas and central areas of communes and towns; Rate of natural population growth and mechanical population growth of the district in 2018 is $27.15 \%$. The number of people at working age in 2018 was 27,490 people, accounting for $58.3 \%$ of the total average population, of which: 24,101 rural workers, urban workers: 3,389 people; The number of people at working age is 27,017 people, accounting for $98.3 \%$; in which female workers: 15,612 people, accounting for $57.78 \%$, the rate of trained workers is $38.86 \%$. The agricultural sectors are the main occupation and employment of workers; The trade and service sector attract a large number of female workers (Statistics Office, Dien Bien Province, Vietnam).

Muong Cha district currently has 13 ethnic groups living in which the majority are ethnic minorities (accounting for 94.7\%), of which Thai people account for $22.33 \%$, Mong people account for $59.73 \%$, ethnic minorities Kinh group accounts for $5.3 \%$, the rest are other ethnic groups such as the Kho $\mathrm{Mu}$, Ha Nhi, Dao, Hoa, Khang diverse customs and practices, unprofessional labor practices also poses many difficulties in developing and improving capacity in labor (Department of Statistics Dien Bien Province, Vietnam).

Muong Cha district still has a lot of shortcomings in both quantity and quality of labor, in addition to the workforce lacks practical experience, lack of knowledge on applying advanced science and technology to production. export. With the current human resource situation, the labor skills of Muong Cha cannot meet the requirements of the district's socio-economic development at present as well as in the future.

* Capital: 
Table 1. Capital construction investment capital in Muong Cha district, Dien Bien province in the period of 2018-2020 (Unit: Million Dong)

\begin{tabular}{|c|c|c|c|c|c|}
\hline No. & $\begin{array}{l}\text { Program name and } \\
\text { capital }\end{array}$ & 3 years in total & 2018 & 2019 & 2020 \\
\hline & Total capital & $300,449.57$ & $117,972.17$ & $77,296.75$ & $105,180.65$ \\
\hline \multirow[t]{2}{*}{1} & $\begin{array}{l}\text { Capital sources for capital construction } \\
\text { and revenue from land use }\end{array}$ & $84,054.44$ & $28,289.17$ & $26,991.27$ & $28,774.00$ \\
\hline & Proportion (\%) of total capital & 27.98 & 23.98 & 34.92 & 27.36 \\
\hline \multirow[t]{2}{*}{2} & Targeted funding is from the NSTW & $18,020.00$ & $15,520.00$ & $2,500.00$ & 0.00 \\
\hline & Proportion (\%) of total capital & 6.00 & 13.16 & 3.23 & 0.00 \\
\hline \multirow[t]{2}{*}{3} & Grants provided by the Government of Ireland & $8,087.25$ & $4,000.00$ & $4,087.25$ & 0.00 \\
\hline & Proportion (\%) of total capital & 2.69 & 3.39 & 5.29 & 0.00 \\
\hline \multirow[t]{2}{*}{4} & $\begin{array}{l}\text { School structure, classrooms and public } \\
\text { houses for teachers (Government bonds) }\end{array}$ & $61,443.51$ & $30,360.00$ & $8,655.51$ & $22,428.00$ \\
\hline & Proportion (\%) of total capital & 20.45 & 25.73 & 11.20 & 21.32 \\
\hline \multirow[t]{2}{*}{5} & NTP for Sustainable Poverty Reduction & $90,414.10$ & $25,833.00$ & $25,592.67$ & $38,988.43$ \\
\hline & Proportion (\%) of total capital & 30.09 & 21.90 & 33.11 & 37.07 \\
\hline \multirow[t]{2}{*}{5.1} & Program 135 & $37,586.77$ & $11,211.00$ & $12,511.77$ & $13,864.00$ \\
\hline & $\begin{array}{l}\text { - In which: Capital contributed by } \\
\text { the community }\end{array}$ & 170.00 & 45.00 & 60.00 & 65.00 \\
\hline \multirow[t]{2}{*}{5.2} & The program is under Decision No. 293 / TTg & $52,827.33$ & $14,622.00$ & $13,080.90$ & $25,124.43$ \\
\hline & $\begin{array}{l}\text { - In which: Capital contributed by } \\
\text { the community }\end{array}$ & 145.00 & 0.00 & 70.00 & 75.00 \\
\hline \multirow[t]{3}{*}{6} & $\begin{array}{l}\text { National target program to build a } \\
\text { new countryside }\end{array}$ & $38,430.27$ & $13,970.00$ & $9,470.05$ & $14,990.22$ \\
\hline & Proportion (\%) of total capital & 12.79 & 11.84 & 12.25 & 14.25 \\
\hline & $\begin{array}{l}\text { - In which: Capital contributed by } \\
\text { the community }\end{array}$ & $3,790.67$ & $1,365.00$ & 935.45 & $1,490.22$ \\
\hline
\end{tabular}

Source: Department of Finance and Planning, Muong Cha District, Dien Bien Province, Vietnam

Table 1 shows that the capital source of the National Target Program on New Rural Construction in Muong Cha District is still low compared to other sources of investment in the district. However, the investment capital of the program has increased year by year, but in 2019 alone, the program's capital decreased in line with the general trend, but the proportion of the capital from the NTP on New Rural Construction compared to the total investment The district's growth rate is still increasing year by year from $11.84 \%$ in $2018,12.25 \%$ in 2019 and $14.25 \%$ by 2020 . This is one of the important capital sources, building many important infrastructures work in extremely difficult communes in the district such as roads, irrigation systems, technical and civil infrastructure. (classroom houses, communal culture houses, villages, hamlets), contributing to step by step perfecting the infrastructure system of communes in the district according to the New Rural criteria. The capital structure of the Program consists of 2 main sources: the central budget source and the contributed capital of the community, these are the two basic sources of capital for the implementation of the New Rural Program in the area of Muong Cha district. Although the capital contribution of the community is not much but it is of great significance to the New Rural program, it shows the spirit of enthusiasm, voluntary contribution of the people and is shown in detail in table 2. 


\section{Mll Macrothink}

Environmental Management and Sustainable Development

ISSN 2164-7682

2021, Vol. 10, No. 2

Table 2. Structure of investment capital of the National Target Program on New Rural Construction in Muong Cha District, Dien Bien Province, Vietnam, period 2018-2020 (Unit: Million Dong)

\begin{tabular}{|l|l|l|l|l|l|}
\hline No. & Capital & 3 years in total & $\mathbf{2 0 1 8}$ & $\mathbf{2 0 1 9}$ & $\mathbf{2 0 2 0}$ \\
\hline & Total & $\mathbf{3 8 , 4 3 0 . 2 7}$ & $\mathbf{1 3 , 9 7 0 . 0 0}$ & $\mathbf{9 , 4 7 0 . 0 5}$ & $\mathbf{1 4 , 9 9 0 . 2 2}$ \\
\hline 1 & Central budget & $34,639.60$ & $12,605.00$ & $8,534.60$ & $13,500.00$ \\
\hline & Proportion (\%) of total capital & 90.14 & 90.23 & 90.12 & 90.06 \\
\hline 2 & Community contributions & $3,790.67$ & $1,365.00$ & 935.45 & $1,490.22$ \\
\hline & Proportion (\%) of total capital & 9.86 & 9.77 & 9.88 & 9.94 \\
\hline
\end{tabular}

Source: Department of Finance and Planning, Muong Cha District, Dien Bien Province, Vietnam

The central budget accounts for more than $90 \%$ of the total capital of the New Rural program, this is also the common situation of the poor mountainous districts of Dien Bien province, the source of revenue is low, the budget depends entirely on the central budget. Therefore, in the process of building the Socio-Economic Development Plan, the public investment plan, the plan to build and complete the program's criteria and the annual plan for the district's capital allocation is always passive, Because the district's actual capital needs are very large, but resources are limited, the implementation of the program has not achieved the desired results.

4.2.3 Managing Capital for Building a New Countryside in Muong Cha District, Dien Bien Province, Vietnam

* Management of preparation and approval of budget estimates (preparation and distribution of capital plans)

The allocation of investment capital estimates for the new Rural program is in the general budget allocation plan of Muong Cha district, the District Department of Finance and Planning always monitors and closely manages the project works and controls. Timely adjust investment capital plans for works in need, reduce plans for projects that cannot be implemented or with low efficiency. Based on the provisions of the Law on State Budget 2015 and related guiding documents, every year, the Muong Cha District Finance - Planning Department has made a plan to allocate investment capital sources for the Rural Construction Program. New in the district's general budget estimate for the People's Committees of communes in the area. Ensure that the capital is allocated on time and on schedule for the People's Committees of communes to disburse and pay for projects in accordance with regulations.

The allocation structure of investment capital under the program has been focused relatively harmoniously, in order of priority: 1 is a group of completed projects, 2 is a group of transitional projects, 3 is a group of new construction projects, details are as follows: 
Table 3. Structure of investment capital sources (NSTW sources) under the National Target Program on New Rural Construction in Muong Cha District, Dien Bien Province in the period of 2018-2020, by project group

\begin{tabular}{|l|l|l|l|l|l|l|l|}
\hline \multirow{2}{*}{ No. } & Project type & $\mathbf{2 0 1 8}$ & $\mathbf{2 0 1 9}$ & $\mathbf{2 0 2 0}$ \\
\cline { 3 - 8 } & & Plan & $\begin{array}{l}\text { Proportion } \\
(\boldsymbol{\%})\end{array}$ & Plan & $\begin{array}{l}\text { Proportion } \\
(\boldsymbol{\%})\end{array}$ & Plan & $\begin{array}{l}\text { Proportion } \\
(\boldsymbol{\%})\end{array}$ \\
\hline 1 & Completed projects & $1,980.34$ & 15.71 & 0 & 0.00 & 0 & 0.00 \\
\hline 2 & Transition project & $2,174.66$ & 17.25 & $1,601.78$ & 18.96 & $1,911.64$ & 14.16 \\
\hline 3 & New K /c project & $8,450.00$ & 67.04 & $6,848.22$ & 81.04 & $11,588.36$ & 85.84 \\
\hline & Total & $\mathbf{1 2 , 6 0 5 . 0 0}$ & $\mathbf{1 0 0 . 0 0}$ & $\mathbf{8 , 4 5 0 . 0 0}$ & $\mathbf{1 0 0 . 0 0}$ & $\mathbf{1 3 , 5 0 0 . 0 0}$ & $\mathbf{1 0 0 . 0 0}$ \\
\hline
\end{tabular}

Source: Department of Finance and Planning, Muong Cha District, Dien Bien Province, Vietnam

Table 3 shows that, Muong Cha district has focused on a relatively harmonious allocation, the group of completed projects is often prioritized to arrange complete payment, in order to resolve outstanding capital construction debts; followed by a group of transition projects with about $14 \%$ to $19 \%$ of total funding; Finally, a group of new start-up projects are allocated over $60 \%$ of the total capital. The capital plan allocation ratio for project groups is set on the basis of the actual completed and accepted volume of each project, in order to disburse, pay off thoroughly, and completely settle outstanding construction debts. copy each project, avoid arising new debts and minimize the adjustment of the capital plan.

\section{* Manage the status of payment and settlement}

Table 4. Distribution and disbursement of the 3-year New Rural Program capital plan (2018 2020) (Unit: million dong)

\begin{tabular}{|l|l|l|l|l|}
\hline No. & Targets & Plan capital already assigned & Disbursement number & Rate of disbursement / plan \\
\hline 1 & 2 & 3 & 4 & $5=4 / 3$ \\
\hline & Total & $34,639.60$ & $34,409.32$ & 99.34 \\
\hline $\mathbf{1}$ & 2017 & $12,605.00$ & $12,577.88$ & 99.78 \\
\hline & - NSTW & $12,605.00$ & $12,577.88$ & 99.78 \\
\hline $\mathbf{2}$ & 2018 & $8,534.60$ & $8,508.14$ & 99.69 \\
\hline & - NSTW & $8,534.60$ & $8,508.14$ & 99.69 \\
\hline $\mathbf{3}$ & 2019 & $13,500.00$ & $13,323.30$ & 98.69 \\
\hline & - NSTW & $13,500.00$ & $13,323.30$ & 98.69 \\
\hline
\end{tabular}

Source: Muong Cha District State Treasury, Dien Bien Province, Vietnam

Table 4 shows that the disbursement rate of investment capital of the New Rural program in recent years has reached a very high rate (over 98\%), which shows the capital plan allocation and real disbursement progress. Currently, the project meets the requirements of the proposed plan, through which we also see the efforts of the Investor and relevant agencies and departments of the district in the management and use of investment capital. private. That high disbursement rate also shows that the ability to utilize and use the investment capital for the implementation of the Rural Program has been exploited and fully utilized.

Monthly and quarterly, the district People's Committee always organizes briefings between specialized units such as the Department of Finance - Planning, the District State Treasury, 
the District Department of Agriculture and Rural Development and the Committee. commune people to monitor, urge and evaluate the results of disbursement of investment capital under the New Rural Program. In order to then evaluate the work progress of each investor, the progress of completing each project, the cause of the unpaid payment, the ability to disburse, thereby adjusting the capital plan accordingly. Ensure the balance of investment capital, promote the implementation and implementation of projects, avoid stagnant capital that cannot be disbursed, while other projects are in desperate need of capital. However, the capital regulation still has shortcomings, such as usually adjusting the capital plan at the end of the year, especially the end date of the annual capital adjustment, thus creating pressure to disburse capital for District State Treasury agencies.

\subsubsection{Check and Supervise the State Management Activities for New Rural Construction}

The inspection, inspection and supervision of state management activities under the New Rural Construction Program in the district is generally a regular and continuous job and is a function and task of governing bodies. such as: State Audit, Provincial Inspector, Department of Finance, District Inspector, ...

In fact, in the past years in the district, the inspection and examination of the New Rural Construction Program, often done by the District Inspectorate and related agencies and agencies. Every year, with his responsibility, the district inspector always advises the district People's Committee to prepare and approve an inspection plan before December 15 every year and publish it to the units (subject of inspection) know and proactively prepare content and documents for the inspection process.

The works under the New Rural Program in the district in the period of 2018 - 2020 are small-scale, uncomplicated technical works, with a total investment of less than 3 billion VND invested by the Commune People's Committee. and the program's investment capital source belonging to the commune budget. Therefore, the inspection process of investment capital under the program is usually only one of the inspection contents of the district Inspectorate to the commune-level budgeting unit.

Based on the inspection plan approved by the district People's Committee, in the period of 2018 - 2020, on average, there are 4 communes subject to inspection each year, including the inspection of investment capital sources of the Agriculture program. new village. The inspection and examination of the New Rural Program in the period 2018 - 2020 in the district is conducted regularly and continuously. In the period of 2018 - 2020, district inspectors have conducted 11 inspections of commune-level budgeting units, of which 15 new Rural works have been inspected, with the post-inspection discounted value. 158.6 million VND. The main cause of the deduction is due to the difference in the unit price of materials, actual construction material norms compared to the approved estimate, the volume of acceptance is not close to the reality ... Investigation has contributed to preventing mistakes, combating wasteful losses, preserving capital for the budget (Inspector of Muong Cha District, Dien Bien Province). 
4.3 General Assessment of State Management on New Rural Construction in Muong Cha district, Dien Bien province, Vietnam

\subsubsection{Results Achieved}

- The New Rural Program is always concerned and directed promptly by the District Party Committee, People's Council, and District People's Committee. Every month, the district-level New Rural Program Steering Committee holds a briefing meeting between relevant agencies and units in order to monitor, urge and grasp the implementation of the program, so it is timely. solve difficulties and problems arising in the process of new Rural construction and the implementation progress of each project

- The basic management of the National Target Program on New Rural Construction in Muong Cha District has complied with the State's policies and resolutions and relevant guiding documents.

- The management of new rural construction in Muong Cha district is always concerned, monitored and urged in time, so issues related to the implementation process are always resolved quickly, neatly, finish and always achieve a high rate (over 98\%). Priority is given to allocating capital sources for completed and receiving works, so there is no outstanding capital construction. There is no stagnation and excess investment capital.

- The management is done fairly, objectively, without bias, priorities, no individual interests or group interests; The implemented projects are discussed, openly and democratically before the people, so the program always receives the response and active contribution of the people in many different forms, such as: workdays, donation of land, property on land.

Table 5. Results of the implementation of the New Rural Program in the period 2018 - 2020 of communes in Muong Cha district, Dien Bien province, Vietnam

\begin{tabular}{|l|l|l|l|l|l|}
\hline \multirow{2}{*}{ No. } & \multirow{2}{*}{ Unit name } & \multirow{2}{*}{ Unit } & \multicolumn{3}{|l|}{ Results achieved in the period of 2018-2020 } \\
\cline { 4 - 6 } & & & $\mathbf{2 0 1 8}$ & $\mathbf{2 0 1 9}$ & $\mathbf{2 0 2 0}$ \\
\hline 1 & Muong Muong Commune & Criteria & 8 & 8 & 15 \\
\hline 2 & Na Sang Commune & Criteria & 7 & 7 & 8 \\
\hline 3 & Sa Lông Commune & Criteria & 10 & 10 & 11 \\
\hline 4 & Huoi Leng Commune & Criteria & 6 & 6 & 6 \\
\hline 5 & Muong Tung Commune & Criteria & 5 & 5 & 6 \\
\hline 6 & Xa Hua Ngai & Criteria & 6 & 7 & 7 \\
\hline 7 & Xa Tong Commune & Criteria & 5 & 5 & 6 \\
\hline 8 & Pa Ham Commune & Criteria & 5 & 6 & 9 \\
\hline 9 & Nam Nen Commune & Criteria & 7 & 8 & 9 \\
\hline 10 & Huoi Mi Commune & Criteria & 3 & 4 & 5 \\
\hline 11 & Ma Thi Ho Commune & Criteria & 7 & 8 & 8 \\
\hline & Total & Criteria & $\mathbf{6 9}$ & $\mathbf{7 4}$ & $\mathbf{9 0}$ \\
\hline & BQ criteria/commune & Criteria & $\mathbf{6 . 2 7}$ & $\mathbf{6 . 7 3}$ & $\mathbf{8 . 1 8}$ \\
\hline
\end{tabular}

Source: Department of Agriculture and Rural Development, Muong Cha District, Dien Bien Province, Vietnam

Table 5 shows that, in the period of 2018 - 2020, the whole district does not have a commune meeting 19 criteria; 1/11 communes achieve 15-18 criteria; 1/11 communes meet 10-14 
criteria; 9/11 communes meet 5-9 criteria; no commune meets less than 5 criteria. Thus, after 4 years of implementing the program, the whole district reached 90 criteria, increasing 21 criteria compared to 2017; averagely 7 criteria per year, the average annual growth rate is 0.64 criteria / commune (Department of Agriculture and Rural Development, Muong Cha District, Dien Bien Province, Vietnam).

- The political system, security and order in the countryside have been maintained, rural transport infrastructure, irrigation, culture, education and health have been gradually improved. Production development activities have formed a number of effective operating models to increase people's income, create a basic foundation for the movement to build a New Rural.

\subsubsection{Some Limitations}

- The district-level New Rural Program Steering Committee is a non-specialized agency, the head of the steering committee is a district vice president, the standing steering committee is the head of the district Department of Agriculture and Rural Development, a member of the steering committee leaders are cadres, civil servants from other departments in the district, operating under part-time mode, so the process of operation, discussion and exchange of information of the Steering Committee is not regular and continuous; Steering committee briefings often do not have enough members. Because many members are in different agencies, it is difficult to arrange and arrange work to attend the meeting.

Although certain results have been achieved, there are still many difficulties and challenges in the implementation of the national program on new rural construction in Muong Cha district. It is worth mentioning that these completed criteria are mostly based on the State's support through national programs and projects.

- The mobilization of people in rural construction only stops at donating land and contributing labor days. The production model is focused on building, but the organization and deployment of the replication only stop at a small group of participants, not pervasive to create a large quantity of high-quality and low-quality goods. according to market requirements to promote local economic development.

- Other criteria, such as cultural facilities, environment, rural markets ... also have their own difficulties. In addition, the need for human resources to invest in the implementation of the major program goals in Muong Cha is also lacking. Most of the officers in charge are part-time, so they are confused in the implementation stage.

\subsubsection{The Causes of the Limitations}

- Given the conditions of border communes, there are many limitations in the base class for socio-economic development; people mainly live on agricultural development; the application of scientific advances in production is still limited, leading to low economic efficiency;

-With wide natural conditions and home to many ethnic minorities, the awareness of the people about the new rural construction program is still limited. Not to mention there are 
people who do not even know the meaning of the new rural construction program.

- Besides, the contingent of commune officials, the limited operating capacity leads to ineffective direction of programs and projects.

- Given the difficult conditions of the border district and the high rate of poor households, it is very difficult to mobilize contributions for new rural construction; Most of the resources are expected to be invested by the state.

\section{Recommend Some Solutions to Improve State Management in Building a New Countryside in Muong Cha District, Dien Bien Province, Vietnam}

5.1 Strengthen Propaganda and Dissemination of Guidelines and Policies of the State on Building a New Countryside

The district steering committee should pay special attention to propaganda and advocacy and this is considered as the most important task in the organization and implementation of the New Rural Construction Program of all levels, the government and specialized departments, to raise awareness for the party committees, party organizations, authorities at all levels and each citizen.

Actively mobilize people to study, unite to implement a civilized lifestyle, cultural families; In the villages, population groups have established self-management team to protect the environment, ensure security and order, reconciliation team with the task of preserving environmental sanitation, collecting waste; mobilize people to strictly abide by the laws and policies of the State ...

5.2 Strengthening Organizational Structure, Fostering a Contingent of Officials and Implementing State Administration and Management on the Construction of a New Countryside in Muong Cha District, Dien Bien Province

Staff work and the contingent of cadres, especially those at strategic level, play a particularly important role in the management of new rural construction. Recognizing the special important position of cadre work, in resolutions as well as in its practical activities, District Committee should pay attention to cadres work. The managerial staff plays an extremely important role in the construction of a new countryside and is a good factor determining success or failure in the construction process. Therefore, district officials need to meet the basic requirements of certain political, ethical and managerial qualities. In terms of professional capacity, in order to build a new countryside, economic managers must have specialized knowledge in their fields, know how to use and assemble qualified cadres, assign the right jobs, to they promote to create strong collectives together with people to build a new countryside.

\subsection{Review, Supplement and Manage the New Rural Construction Planning in Muong Cha District, Dien Bien Province}

The People's Committee of Muong Cha district, Dien Bien province needs to direct all levels and branches to continue reviewing, supplementing and adjusting the new rural construction 
planning to ensure consistency and have a long-term vision. In the coming time, localities will actively do well the planning work, mobilize resources, step by step invest in building complete socio-economic infrastructure in rural areas, according to the motto "People know, people discuss, people do, people check and people beneficiaries".

The district continues to coordinate with relevant communes and branches to focus on improving the quality and efficiency of rural planning projects. The People's Committee of Muong Cha district should review, adjust and supplement the plan in accordance with the actual conditions of each locality, ensuring the planning requirements of the province for the period of 2021-2026. Department of Construction proposes competent agencies to promulgate specific regulations on planning management, setting up construction landmarks, identifying areas in need of protection and embellishment, embellishment and construction zones. New construction, agricultural production zones ... At the same time, regulations are strictly regulated for areas without approved detailed plans to facilitate local authorities to develop plans, schemes and organizational mechanisms. and direct the good implementation of new rural construction planning tasks in each period.

\subsection{Reform Methods of Mobilizing Resources for New Rural Construction in Muong Cha District, Dien Bien Province}

Mobilizing resources for new rural construction: Diversifying forms of socialization. Proactively exploiting the advantages of the locality to determine resources in new rural construction in addition to the state budget capital, there are also socialized resources, so the district needs to mobilize people with the motto " country and people do it together".

The district needs to thoroughly understand communes that implement well the grassroots democracy regulation so that people know, people do, people discuss, people check, and people enjoy; at the same time, mobilize, actively propagate, mobilize enterprises to participate. calling for support from organizations and departments.

\subsection{Increasing Investment, Building Standards for New Rural Construction in Muong Cha} District, Dien Bien Province

The goals of building a new countryside are: the material and spiritual life of the rural people has been improved rapidly; to develop agriculture and rural areas according to planning, with a synchronous infrastructure system and meeting the long-term development requirements; clean green environment; preserving and promoting the cultural identity of regions; solid political system.

The soft criteria of rural areas are very important, from people's lives, security, social safety, culture, environment and the strength of the political system.

Hard criteria are only the implications of development. That is, the criteria of a new countryside must have characteristics, characteristics and degree suitable for each region, region and locality, not all regions are the same;

Construction of a new countryside must be consistent with the goal of building a model new countryside associated with a civilized urban area; 
Integrate resources from other national target programs and UN sustainable development programs with new rural construction to avoid spreading and wastefulness.

Muong Cha district should base on the guidance of ministries and branches to detail standards to suit natural, social conditions, and climate change in their locality, but must not be lowered. low criteria, standards of criteria.

5.6 Focusing on Checking, Monitoring, Reviewing and Evaluating the Implementation of New Rural Construction in Muong Cha District, Dien Bi Province Paying Attention to Checking, Monitoring, Reviewing and Evaluating the Implementation of New Rural Construction above in Muong Cha District, Dien Bien Province

-The Muong Cha District Party Committee should conduct inspections and thematic supervision on new rural construction, focusing on the development, issuance, and implementation of resolutions, schemes and plans of Party committees, authorities and leaders, direct the implementation of solutions for building a new countryside; exploitation, management and use of resources.

- Implement the democratic regulations at the grassroots level in mobilizing the people's contributions, in managing capital resources and organizing the management and construction of infrastructure works in the villages, villages ...

- On the basis of properly assessing the current situation of limitations, the District Party Committee has issued resolutions to improve the quality of the achieved criteria and maintain sustainable development in the following years, promoting traditional; building a new cultural lifestyle for cadres, party members and the people of the whole district.

- To promptly rectify the leadership and direction, especially in the development of projects and plans, and mobilize resources to speed up the progress and improve the quality of the district's new rural construction.

\section{Conclusion}

With overall solutions to strengthen propaganda and dissemination of laws and policies of the State on building a new countryside; To consolidate the organizational structure, foster the contingent of cadres and perform the administration and management of new rural construction; Renovating modes of mobilizing resources for new rural construction; Investment, building standards for new rural construction; Focusing on checking, monitoring, reviewing and evaluating the implementation of new rural construction; ... The program on new rural construction in Muong Cha district, Dien Bien province, Vietnam will have many prosperity, step up the implementation of poverty reduction in ethnic minority areas, shorten the development gap between ethnic groups, gradually reduce extremely difficult areas, maintain the block of great unity of ethnic groups in the process of international economic integration.

\section{References}

Anna, L. A. (2009). Building a New Socialist Countryside”- Only a Political Slogan? [Online] 
Available: https://doi.org/10.1177/186810260903800403

Circular No. 28/2012 / TT-BTC dated February 24, 2012 of the Ministry of Finance on the process of controlling the payment of investment capital of the State Treasury system. (2012) (Vn.).

Circular No. 41/2013 / TT-BNNPTNT dated October 4, 2013 of the Ministry of Agriculture and Rural Development guiding the implementation of the national set of criteria for a new countryside. (2013) (Vn.).

Circular No. 85/2017 / TT-BTC dated 15/8/2017 of the Ministry of Finance regulating the settlement of the use of investment capital from the State budget according to the annual budget year. (2017) (Vn.).

Dao, P. (2020). Ha Nam improves the quality of new rural construction. Retrieved from https://nhandan.com.vn/dang-va-cuoc-song/ha-nam-nang-cao-chat-luong-xay-dung-nong-tho n-moi-629105/

Decision No. 1587 / QD-UBND dated December 23, 2016 of the People's Committee of Dien Bien province on the approval of the program on new rural construction of Dien Bien province (2016) (Vn.).

Decision No. 1600 / QD-TTg dated August 16, 2016 of the Prime Minister approving the National Target Program on New Rural Construction. (2016) (Vn.).

Decision No. 1980 / QD-TTg dated October 17, 2016 of the Prime Minister on promulgating the national set of criteria for new rural communes for the 2016-2020 period. (2016) (Vn.).

Dien Bien Statistical Office (2019). Dien Bien Statistical Yearbook 2019. Hanoi, Statistical Publishing House (Vn.).

General collection (2011). Joining hands to build a new countryside. [Online] Available: http://www.cuchi.hochiminhcity.gov.vn/tin_tuc_su_kien/Lists/Posts/Post.aspx?List=d67a9c8 b\%2D43ce\%2D4e14\%2Db95f\%2D6ad521548308\&ID=812\#: :text=X\%C3\%A1 \% 20\% C4\% 91\% E1\% BB\% 8Bnh\% 20m\% E1\% BB\% A5c\% 20ti\% C3\% AAu\% 20x\% C3\% A2y, b\% E1\% BA\% A3o\% 20v\% E1\% BB\% 87\% 20m \% C3\% B4i\% 20 million\% C6\% B0\% E1\% BB\% 9Dng\% 20 birth

Japan North (2020). Rural economic development to build a new countryside. [Online] Available: http://baochinhphu.vn/Tin-noi-bat/Phat-trien-kinh-te-nong-thon-de-xay-dung-nong -thon-moi/397847.vgp

Kristen E. L. (2015). China's New Socialist Rural Construction Campaign: Village Modernization, Farmers Council and Ganzhou Rural Development Model. [Online] Available: https://www.cambridge.org/core/journals/china-quarterly/article/abs/chinas-campaign-to-buil d-a-new-socialist-countryside-village-modernization-peasant-councils-and-the-ganzhou-mod el-of-rural-development / D9A5DB8DF97078B6595B2250CEABE12A

Law on State Budget No. 83/2015 / QH13 dated June 25, 2015 of the National Assembly of 


\section{Macrothink \\ Environmental Management and Sustainable Development \\ ISSN 2164-7682 \\ 2021, Vol. 10, No. 2}

the Socialist Republic of Vietnam. (2015) (Vn.).

Minh, T. (2017). 9 solutions for new rural construction until 2020. [Online] Available: https://infonet.vietnamnet.vn/chuyen-de/9-giai-phap-xay-dung-nong-thon-moi-den-nam-2020 - 110798.html

Resolution No. 100/2015 / QH13 dated 12/11/2015 of the National Assembly on approving the policy of investment in national target programs for the 2016-2020 period. (2015) (Vn.).

Song, Y. (2012). Building New Rural Areas in China: Policy and Practice. [Online] Available: https://www.amazon.com/New-Countryside-Construction-China-Practices/dp/7109165167

Thuy, H. (2017). Regulate conditions to recognize the locality to meet the new rural standards. [Online] Available:

https://www.quangnam.gov.vn/CMSPages/BaiViet/Default.aspx?IDBaiViet=22178

Tue, M. (2019). Key tasks and solutions to build a new countryside in the coming time in Vinh Phuc. [Online] Available:

https://moha.gov.vn/danh-muc/nhiem-vu-trong-tam-va-giai-phap-thuc-hien-xay-dung-nong-t hon-moi-trong-thoi-gian- I-ear-happy-happy-41293.html

Wen (2011). Building New Rural Areas and Developing Sustainable Rural Settlement in China. [Online] Available:

https://www.researchgate.net/publication/269389413_New_Countryside_Construction_and_S ustainable_Rural_Settlement_Development_in_China

\section{Copyright Disclaimer}

Copyright for this article is retained by the author(s), with first publication rights granted to the journal.

This is an open-access article distributed under the terms and conditions of the Creative Commons Attribution license (http://creativecommons.org/licenses/by/4.0/). 